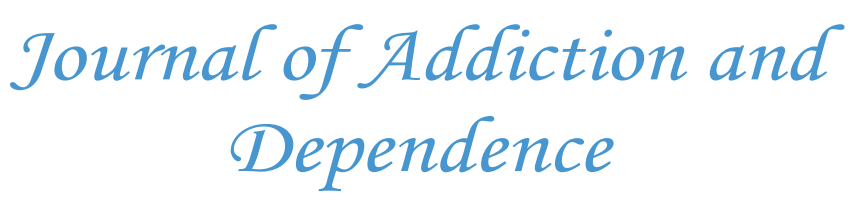

\title{
Three High Doses of Buprenorphine in the Treatment of Prolonged and Severe Opium Dependence: A New Access
}

\author{
Jamshid Ahmadi*, Mojgan Koushamohammadi, Mina Sefidfard Jahromi, Zahra Ehsaei
}

Substance Abuse Research Center, Shiraz University of Medical Sciences, Shiraz, Iran.

*Corresponding author: Jamshid Ahmadi, Professor and Founding Director, Substance Abuse Research Center, Shiraz University of Medical Sciences, Shiraz, Iran, E-mail: Jamshid_Ahmadi@yahoo.com

\begin{abstract}
Background: Heavy and prolonged opium dependence is a progressing problem in the East. For the treatment of opium dependence, buprenorphine can be prescribed less frequently than daily due to its long half-life.

Objective: To administered three high doses buprenorphine instead of daily use to reduce probability of buprenorphine dependence.

Results: The prescription of three high doses of 32, 96 and $72 \mathrm{mg}$ buprenorphine was tolerated conveniently. Administration of high doses of buprenorphine completely improved opium withdrawal symptoms.

Discussion: The current work indicated that few high doses of buprenorphine, could be adequate and satisfactory for the improvement of heavy and prolonged opium dependence.

Conclusions: We came to this result that administration of high dose buprenorphine looks to be convenient, acceptable and tolerable. More research studies should be of interest as high buprenorphine doses are getting more general clinically. We concluded that three doses of 32, 72 and $96 \mathrm{mg}$ buprenorphine, could be adequate for the improvement of severe opium use disorder.
\end{abstract}

Received Date: November 1, 2016

Accepted Date: December 8, 2016

Published Date: December 14, 2016

Citation: Ahmadi, J. Three High doses of Buprenorphine in the treatment of prolonged and severe Opium Dependence: A New Access. (2017) J Addict Depend 3(1): $131-133$.

DOI: $10.15436 / 2471-061 X-17-034$

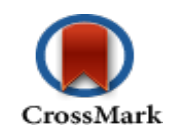

Keywords: High dose buprenorphine; Opium withdrawals

\section{Introduction}

Usage of opium has a long history of remedy intentions in many parts of the East especially Asia ${ }^{[1-3]}$. Opium derivatives, mainly buprenorphine has been under extensive research for the treatment of opioid use disorders ${ }^{[4]}$. Probing for the treatment of opium addiction, contrasting methadone with buprenorphine, disclosed that buprenorphine is more positive than methadone $^{[5-7]}$. Furthermore, studies illuminates that efficacy of $8 \mathrm{mg}$ buprenorphine is parallel to 60 methadone ${ }^{[8]}$.

Buprenorphine, a medication with mixed agonist-antagonist characteristics, has been beneath rating as a potential detoxification drug for the management of opioids addiction. Evaluations have distinguished buprenorphine as an agonist of mu receptor, and as a strong K-receptor antagonist ${ }^{[9-12]}$. A medication with partial agonist property is presented as a compound for which even at total saturation of the receptor system their effect is already less than the maximal achievement preparable with full agonists. Thus buprenorphine has less intrinsic activity at preceptors comparing to full agonists ${ }^{[13-15]}$. In man, buprenorphine elicit typical long duration effects of mu opioid agonist, including analgesia, euphoria, pupillary constriction and sedation.

Moreover, a ceiling on the buprenorphine respiratory depressant and euphoric effects would produce more safety in clinical practice. Since respiratory depression is the main lethal adverse effect of opioids, hence it would be highly favorable to have a forceful opioid with a lower potential for making this side effect $^{[14-16]}$.

According to the new information, medical and mental disease are going upward universally ${ }^{[17-30]}$. 
Focusing on mental disorders, substance use disorders, have been contemplated as a developing dilemma ${ }^{[31]}$. Concentrating on the published research works, opioids jointed disorders and stimulants allied problems have resulted more admissions to the psychiatric centers ${ }^{[32-40]}$.

Now a days, buprenorphine is mainly used for the treatment of opioid withdrawal symptoms ${ }^{[4]]}$.

We examined three high doses of buprenorphine for the management of chronic opium dependence.

We ourselves compose a Visual Analogue Scale (VAS) and checked it empirically for reliability and validity to rate and categorize the opium withdrawals including pain and craving, limiting from 0 to 10 ( 0 means no craving or pain at all and 10 means severe temptation and craving all the time). Besides we constructed the subject exactly about marking.

Validated and reliable Craving Scale: 0-1-2-3-4-5-6-7-8-9$10^{[31,32]}$.

\section{Patient picture}

We would like to present our patient with heavy and prolonged dependency to opium who responded successfully to three high doses of buprenorphine. EA was a 34-year old single, unemployed with university education. He resided in the south of Iran, capital city of Shiraz, province of Fars with his parents. He commenced smoking tobacco and opium at age of 19. EA stepwise increased the dosage of opium so that he became dependent to opium. He gave history of occasional abuse of clonazepam and methadone. Since 10 years prior to admission he little by little developed anxiety, restlessness, obsessions isolation, hopelessness and depressed mood. He gave history of 20 short times of opium abstinences. He reported history of psychiatric disorders in his sister. He referred to the outpatient clinic of Ebnesina psychiatric hospital and was hospitalized in dual diagnosis ward.

During complete psychiatric interview and precise examination, he had restlessness, agitation, anxiety, depression and isolation. Regarding comprehensive and detailed physical and neurological examinations we did not find any pathology. Urine toxicology test (Thin Layer Chromatography, TLC) was positive for morphine and methadone. Tests of serology for viral markers (HIV, $\mathrm{HCV}$ and $\mathrm{HB} \mathrm{Ag}$ ) did not demonstrate abnormal findings.

Based on medical, psychiatric, and substance use history and DSM-5 criteria, he was diagnosed as "opioid induced depressive disorder with severe use disorder. At the time of admission and based on his symptoms we administered olanzapine $20 \mathrm{mg}$, trazodone $50 \mathrm{mg}$ and venlafaxine $150 \mathrm{mg}$ per day to treat depression, anxiety and insomnia.

Since he was suffering from significant pain and craving, so in the $2^{\text {nd }}$ day of admission he received one dose of $32 \mathrm{mg}$ sublingual buprenorphine. Moreover, one day later, in the $3^{\text {rd }}$ day of admission, he still was complaining of withdrawal symptoms so, we gave him a dose of $96 \mathrm{mg}$ buprenorphine. He was pretty good till $5^{\text {th }}$ day of hospital, but developed pain and craving. Therefore, he received one dose of $72 \mathrm{mg}$ buprenorphine. Few hours later his symptoms disappeared. Since he did not report any symptoms of withdrawal, he was discharged nine days later.

The mean scores for opioid (opium) withdrawal pain for 13 days of hospital admission were $1 \& 0 \& 1 \& 1 \& 2 \& 0$ $\& 0 \& 0, \& 0 \& 0 \& 0 \& 0 \& 0$, respectively.
With regards to the precise interview, monitoring and scoring (3 times a day) for opium withdrawal pain, EA experienced and reported a descending level of pain after receiving three doses (32 mg, $96 \& 72 \mathrm{mg}$ ) of buprenorphine.

The mean scores of opioid (opium) withdrawal craving for 13 days of hospital admission were $3 \& 7 \& 8 \& 3 \& 6 \& 0$ $\& 0 \& 0, \& 0 \& 0 \& 0 \& 0 \& 0$, respectively. After 13 days of hospitalization he was discharged without having any withdrawal temptation and pain.

\section{Discussion and conclusion}

We could not find any published study with three high doses of buprenorphine. This work demonstrated that three high doses of buprenorphine (32, 72 and $96 \mathrm{mg}$ ) could be adequate for opium withdrawal symptoms treatment. Hence, this report could be an important addition to the literature. We reached to this fact that administration of sublingual buprenorphine in high dose looks tolerable and helpful. Farther investigation should be of interest as high buprenorphine doses are clinically getting more popular. We concluded that three consecutive high doses of buprenorphine can be adequate in the treatment of severe opioids withdrawal symptoms. It seems that administering three high doses of buprenorphine is more powerful than daily buprenorphine administration for a long time.

Acknowledgement: None to be stated.

Conflict of Interests: None to be declared. 


\section{References:}

1. Brian, J. Opium and infant-sedation in $19^{\text {th }}$ century England. (1994) Health Visit 67(5): 165-166.

2. Jonnes, J. The rise of the modern addict. (1995) Am J public Health 85: 1157-1162.

3. Sadock, B., Sadock, V., Ruiz. P. (Editors) Kaplan \& Sadock'S Synopsis of Psychiatry. (2015) Lippincott Williams and Wilkins.

4. Jasinski, D.R., Pevnick, J.S., Griffith, J.D. Human pharmacology and abuse potential of the analgesic buprenorphine: a potential agent for treating narcotic addiction. (1978) Arch of Gen Psychiatry 35(4): 501-516.

5. Ling, W., Charuvastra, C., Collins, J. F., et al. Buprenorphine maintenance treatment of opiate dependence: a multicenter randomized clinical trial. (1998) Addiction 93(4): 475-486.

6. Ling, W., Rawson, R.A., Compton, M.A. Substitution pharmacotherapies for opioid addiction: from methadone to LAAM and buprenorphine. (1994) J of Psychoactive Drugs 26(2): 119-128.

7. Strain, E.C., Stitzer, M.L., Liebson, I.A., et al. Comparison of buprenorphine and methadone in the treatment of opioid dependence. (1994) Am J Psychiatry 151(7): 1025-1030.

8. Johnson, R.E., Jaffe, J.H., Fudala, P.J. A controlled trial of buprenorphine treatment for opioid dependence. (1992) JAMA 267(20): 27502755.

9. Lewis, J.W. Buprenorphine. (1985) Drug Alcohol Depend 14(3-4): 363-372.

10. Jasinski, D.R., Fudala, P.J., Johnson, R.E. Sublingual versus subcutaneous buprenorphine in opiate abusers. (1989) Clin Pharmacol Ther 45(5): 513-519.

11. Martin, W.R., Eades, C.G., Thompson, J.A., et al. The effects of morphine- and nalorphine like drugs in the non-dependent and morphine dependent chronic spinal dog. (1976) J Pharmacol Exp Ther 197(3): 517-32.

12. Cowan, A., Lewis, J.W., MacFarlane, I.R. Agonist and antagonistproperties of buprenorphine: a new antinociceptiveagent. (1977) Br J Pharmacol 60(4): 537-545.

13. Negus, S.S., Dykstra, L.A. Kappa antagonist properties of buprenorphine in the shock titration procedure. (1988) Eur J Pharmacol 156(1): 77-86

14. Leander, J.D. Buprenorphine is a potent Kappa-opioid receptor antagonist in pigeons and mice. (1988) Eur J Pharmacol 151(3): 457-461. 15. Ariens, E.J. Intrinsic activity: partial agonists and partialantagonists. (1983) J Cardiovasc Pharmacol 5: S8-15.

16. Walsh, S.L., Preston, K.L., Stitzer M.L., et al. Clinical pharmacology of buprenorphine: Ceiling effects at high doses. (1994) Clinical Pharmacology \& Therapeutics 55(5): 569-580.

17. Pridmore, S., Ahmadi, J., Majeed, Z.A. Suicide in Old Norse and Finnish folk stories. (2011) Australas Psychiatry 19(4): 322324.

18. Ahmadi, J., Ahmadi, N., Soltani, F., et al. Gender Differences in Depression Scores of Iranian and German Medical Students. (2014) Iran J Psychiatry Behav Sci 8(4): 7073.

19. Pridmore, S., Ahmadi, J. Two cases of 'Type 3' suicide. (2010) Australas Psychiatry 18(5): 426430.
20. Pridmore, S., Ahmdi, J. Usage of download of psychiatry by Muslim countries. (2011) Bulletin of clinical psychopharmacology 21(2): 174.

21. Ahmadi, J., Toobaee, S., Alishahi, M. Depression in nursing students. (2004) J Clin Nurs 13(1): 124.

22. Ahmadi, J., Pridmore, S., Fallahzadeh, M. Neurotic scores in a sample of medical students. (2004) German J Psychiatry 7: 5155.

23. Ahmadi, J. Human and Pain. (1993) Journal of Healthy Society $3(13)$.

24. Ahmadi, J. Behavior therapy and Bio behavior therapy; A comparative view. (19923) Journal of Social Sciences and Humanities of Shiraz University fall and spring $8(1,2)$.

25. Ahmadi, J. A view on Bio behavior therapy. (1992) Journal of Pulse "Specific for Refreshment of Medical Community 2.

26. Ahmadi, J. The Future of Psychiatry (A novel theory and a new approach). (1992) Shiraz, Rahgosha Press, Second edition, Shiraz University of Medical Sciences.

27. Ahmadi, J. Behavior Therapy. (1991) Shiraz, Shiraz University Press, Third edition.

28. Ahmadi, J. Emotion, Feeling and Nonverbal Communication. (1990) Shiraz, Rahgosha Press, Shiraz University of Medical Sciences. 29. Ahmadi, J. Obsessive Compulsive Disorder. (1989) Shiraz, Navid Press, Second edition, Shiraz University of Medical Sciences.

30. Ahmadi, J. Human and Bio-behaviorism (A new theory and approach). (1994) Journal of Healthy Society 3(14).

31. Ahmadi, J. Methylphenidate in the treatment of methamphetamine withdrawal Craving: a novel outcome. (2016) J Drug Abuse 2(1): 12.

32. Ahmadi, J. The Effect of Buprenorphine and Bupropion in the Treatment of Methamphetamine Dependency and Craving. (2015) Br J Med \& Med Res 10(2): 14.

33. Ahmadi, J. Comparing the Effect of Electroconvulsive Therapy, Buprenorphine and Methadone in the Management of Methamphetamine dependency and withdrawal Craving. (2016) J Addict Depend 2(4): 13.

34. Ahmadi, J., Pridmore, S. Zolpidem Dependency. (2016) J Addict Depend 2(4): 1-2.

35. Ahmadi, J. Treatment of Chronic Methadone Dependence with Buprenorphine.(2016) J Addict Depend 2(3): 1- 3.

36. Ahmadi, J. Positive Effect of Low Dose of Buprenorphine in the Treatment of Severe Hashish Withdrawal Craving: An Original Arcade. (2016) J Addict Depend 2(2): 1-3.

37. Ahmadi, J. Cannabis induced psychosis treatment: An original approach. (2016) J Addict Depend 2(2): 1- 2.

38. Ahmadi, J. Pethidine Abuse: A Novel Finding. (2016) J Addict Depend 2(2): $1-3$.

39. Ahmadi, J. Heroin Dependency Treatment: A New Approach. (2015) J Addict Depend 1(2): 1-3.

40. Ahmadi, J. Excellent Outcome of Psychosis Induced by Methamphetamine Intoxication after 20 Sessions of Electro Con $\urcorner$ vulsive Therapy. (2015) J Addict Depend 1(2): 1- 2.

41. Ahmadi, J., Pridmore, S., Ekramzadeh S. Successful Use of Electro Convulsive Therapy in the Management of Methamphetamine Induced Psychosis with onset During Intoxication. (2015) J Addict Depend 1(1): $1-2$.
Ommega Online Publishers

Journal Title: Journal of Addiction and Dependence(JAD)

Journal Short Name: J Addict Depend
ISSN no: 2471-061X

E-mail: addiction.depend@ommegaonline.org

Website: www.ommegaonline.org 